\title{
Concepções de professores sobre brincadeira e sua relação com o desenvolvimento na educação infantil
}

\author{
Gabriela Dal Forno Martins \\ Mauro Luís Vieira \\ Ana Maria Faraco de Oliveira
}

Universidade Federal de Santa Catarina

\begin{abstract}
RESUMO
A presente pesquisa teve como objetivo caracterizar as concepções que professores de educação infantil têm a respeito da importância da brincadeira como parte do processo educativo. Os participantes foram 81 professoras, com idade variando de 18 a 63 anos. Foi utilizada uma escala do tipo Likert, desenvolvida pelos pesquisadores, contendo 42 itens distribuídos em cinco categorias: conceito de brincadeira, relação entre brincadeira e aprendizagem, papel dos professores em situação de brincadeira livre e estruturada, dificuldades encontradas na utilização da brincadeira e valor atribuído à brincadeira para o desenvolvimento global da criança. Os resultados indicaram que: a) os professores concordaram entre si a respeito de aspectos teóricos do conceito e da funcionalidade do brincar; b) existe alto grau de concordância dos professores a respeito da importância do brincar enquanto recurso didático no processo de alfabetização. No entanto, constatou-se heterogeneidade de idéias relacionadas à implementação da brincadeira no cotidiano da educação infantil, incluindo o papel do professor e dificuldades encontradas nesse processo. Nesse sentido, conclui-se que existe uma necessidade de promoção de aperfeiçoamento profissional dos professores que enfatize questões teóricas e práticas, visando uma efetiva utilização da brincadeira no cotidiano da educação infantil.
\end{abstract}

Palavras-chave: brincadeira; desenvolvimento infantil; educação infantil

\begin{abstract}
Teachers' conceptions about play and its relation with development in children's education

The present research aimed to characterize the conceptions that kindergarten teachers have about the importance of play as part of the educative process. A total of 81 teachers aged from 18 to 63 years took part in this research. A Likert-type scale, developed by researchers, was used to collect the data. The forty-two items were distributed into five categories: the concept of play; the relationship between play and learning; the role of the teachers in situations of free and structuralized play; the difficulties found in the use of play and the value attributed to play for the global development of the child. The results indicated that: a) teachers agreed among themselves in relation to theoretical aspects of the concept and functionality of play; and b) there was high degree of agreement among teachers in relation to the importance of play as a didactic resource in the process of teaching children to read and write. However, heterogeneity of ideas related to the implementation of play in the kindergarten was noted, including the role of the teacher and the difficulties found in this process. In sum, it was concluded that there is a need to promote professional improvement of the teachers emphasizing both theory and practice, with the purpose of improving the utilization of play in the kindergarten.
\end{abstract}

Keywords: play behavior; child development; kindergarten

O conceito de brincadeira que enfatiza ser esta uma atividade com um fim em si mesma, iniciada e mantida pela criança pelo simples prazer de brincar nem sempre encontra lugar na educação. Kishimoto (1994) esclarece que isso ocorre em função de a criança ser vista, muitas vezes, como um ser que deve ser apenas disciplinada para a aquisição de conhecimentos em instituições de ensino acadêmico. Porém, o que vem sendo enfatizado é que o brincar, sendo irresistível para a criança, deve ser um meio para educá-la (Dohme, 2003; Kishimoto, 1994, 1999; Volpato, 2002).

Através de investigações científicas, tem-se procurado identificar as percepções e práticas dos professores a respeito da brincadeira, a fim de se discutir a 
introdução da mesma de forma adequada nos currículos e dos benefícios que isso pode trazer. Cooney (2004), em pesquisa realizada na Guatemala, investigou junto a pais e professores suas percepções a respeito da aprendizagem por meio da brincadeira. Os resultados demonstram que a percepção dos adultos acerca da experiência mais adequada para o período pré-escolar inclui a aprendizagem através da brincadeira, portanto, as atitudes de pais e professores não são uma barreira na implementação da brincadeira. As principais barreiras encontradas relacionaram-se à pedagogia e ao ambiente, dentre elas: a grande proporção de crianças por professor, a falta de recursos apropriados para a aprendizagem e ausência de desenvolvimento profissional que enfoque o currículo orientado pela brincadeira.

Hatch e Freeman (1988) relatam que as experiências dos professores de educação infantil refletem o conflito entre suas próprias crenças acerca do desenvolvimento e as reais práticas em sala de aula. Em relação a isso, Goldhaber (1994), baseada em histórias que seus alunos contavam a respeito de sua prática de ensino na educação infantil, descreve algumas dificuldades encontradas na implementação dos conhecimentos a respeito da utilização da brincadeira, tais como a falta de tempo e recursos e, mais significativamente, o fato de o brincar não ser visto como o meio primário para se aprender. Enquanto os estudantes têm sido treinados a valorizar a autonomia das crianças em sua aprendizagem (child-directed) e a brincadeira facilitada pelo professor como um meio de aprender, muitos deles encontram dificuldade de explicar suas práticas para seus colegas, pais dos alunos e administradores (Goldhaber \& Smith, 1993).

Barreiras encontradas na implementação da brincadeira por parte dos professores tornam-se bastante preocupantes na medida em que se considera o professor como sendo o fator mais crítico na determinação da qualidade de um programa de educação infantil (Snider \& Fu, 1990). Várias características dos professores e seus estilos em sala de aula têm sido demonstrados como influentes sobre diferentes aspectos do desenvolvimento infantil. Fein (1978) e Rosen (1974), por exemplo, afirmam que professores que usam estilos particulares de incentivo e intervêm apropriadamente podem melhorar a qualidade de brincadeiras em sala de aula.

Autores exemplificam possíveis ações dos professores consideradas apropriadas quando eles utilizam a brincadeira (Dohme, 2003; Goldhaber; 1994; Kishimoto, 1994; Olsen \& Sumsion, 2000). Para que a intervenção do professor consiga equilibrar as funções lúdica e educativa da brincadeira, é preciso que ele atue de forma a preservar a liberdade da criança. A ação pedagógica intencional do professor deve refletir-se na organização do espaço, na seleção dos brinquedos e na interação com as crianças, desde que não se entre em conflito com a ação voluntária da criança (Kishimoto, 1994). Com relação a esse último aspecto, Corsaro e Schwarz (1991) assinalam a influência dos professores que trabalham com crianças, como parceiros de brincadeiras, produzindo a cultura de pares em direção à reprodução do mundo adulto. Com tudo isso, o papel do professor é alterado: passa a ser um administrador dos alunos, de suas potencialidades, seus ritmos, seus interesses, suas diversidades e as diversas fontes de aprendizagem (Dohme, 2003).

Strickland e Ogle (1990) afirmam que, muitas vezes, professores são observados relativamente não envolvidos nos momentos em que as crianças estão brincando. No entanto, Goldhaber (1994) defende a idéia de que o brincar deve ser visto como algo mais digno de atenção e, nesse sentido, seria de extrema relevância que os professores observassem e se envolvessem com as crianças e seus esforços para compreender o mundo. $\mathrm{O}$ autor baseia sua afirmação na comparação que faz entre o brincar e a ciência: para ele a criança poderia ser comparada a um cientista, o qual, quando brinca utiliza-se de sua criatividade, levanta questionamentos, explora fenômenos com o objetivo de compreendê-los, forma, testa e rejeita hipóteses. Ainda, Olsen e Sumsion (2000) destacam algumas práticas citadas por professores de educação infantil na utilização da brincadeira de faz-de-conta, tais como: monitoramento do número de crianças em relação ao material disponível, observação e escuta dos temas que surgem no decorrer da brincadeira, a fim de estender a experiência de faz-de-conta, determinar quais crianças precisam de assistência para compreender algum conceito e levar a diante as idéias das crianças.

Além de uma formação adequada e um certo gosto pelo brincar, algumas características são essenciais para um professor que utiliza a brincadeira, tais como: entusiasmo, criatividade, alegria de viver, aptidão para as relações humanas e a abertura de espírito, complementados pela formação contínua (Leif \& Brunelle, 1978). Nesse sentido, o educador deve brincar e participar das brincadeiras, demonstrando não só o prazer de fazê-lo, mas estimular as crianças para tais ações. 
Diante da relevância da brincadeira apontada por diversos autores, ela deveria ser mais estudada pelos educadores como mais uma alternativa pedagógica a serviço de desenvolvimento integral da criança (Negrine, 1994). No entanto, é preciso antes ter claro qual o nível de conhecimento conceitual atual dos professores a respeito da brincadeira e de que forma eles vêm utilizando-a. Diante de tudo isso, a presente pesquisa teve como objetivo principal caracterizar as concepções que professores de educação infantil têm a respeito da importância da brincadeira inserida nos processos educativos, incluindo o conceito que possuem de brincadeira, o papel exercido quando dela se utilizam, o valor atribuído à brincadeira para o desenvolvimento físico, cognitivo, social e emocional e as dificuldades encontradas na implementação da brincadeira no cotidiano da educação infantil.

\section{MÉTODO}

\section{Participantes}

Os participantes foram 81 professores de creches da rede pública e privada e de escolas de ensino fundamental de duas cidades do litoral catarinense. Dos participantes, 91,4\% atuavam apenas na pré-escola e os restantes atuavam tanto na Educação Infantil como no Ensino Fundamental. Com relação ao tipo de instituição, $56 \%$ trabalhavam na rede pública, $14 \%$ na rede privada, $1 \%$ em ambas, $28 \%$ em instituição filantrópica e $1 \%$ em outras instituições $\left(\mathrm{n}=80^{1}\right)$.

A idade dos professores variou entre 18 e 63 anos (média de 31,5 anos), dentre os quais $24 \%$ possuíam segundo grau completo, $51 \%$ curso superior incompleto, $11 \%$ curso superior completo e $14 \%$ eram pósgraduados $(\mathrm{n}=79)$. Quanto à faixa etária das crianças com as quais os professores já haviam trabalhado, $64,2 \%$ já haviam trabalhado com crianças em idade pré-escolar, 1,2\% com crianças de Ensino Fundamental, $32,1 \%$ com ambas as idades e 1,2\% estavam em sua primeira experiência na educação $(n=80)$. A maioria dos participantes $(54,3 \%)$ afirmou ter realizado cursos extracurriculares como última forma de capacitação na época de participação da pesquisa. $\mathrm{O}$ restante apontou o próprio curso superior $(18,5 \%)$ como última forma de capacitação, o segundo grau $(12,3 \%)$ e a pós-graduação $(11,1 \%)$, sendo o $\mathrm{n}=78$ para tal questão. O tempo transcorrido após tais cursos variou entre 0 a 60 meses, com média de 5,2 meses e moda de 2 meses.

\section{Instrumento}

Para coleta dos dados, foi desenvolvido pelos pesquisadores um instrumento composto de duas partes: um inventário, a fim de caracterizar o perfil dos participantes e uma escala denominada "Escala de Concepções de Professores sobre Brincadeira e Desenvolvimento na Educação Infantil" (ECP-BDEI). Os itens que compuseram a escala indicavam comportamentos, e foram construídos com base na literatura existente na área e nas respostas de 24 professoras entrevistadas anteriormente em um estudo piloto.

Os 42 itens construídos incluíam tanto a prática dos professores relacionada ao brincar no dia-a-dia na escola, quanto suas crenças e conhecimentos a respeito da brincadeira. É importante enfatizar que alguns itens foram construídos de forma complementar, ou seja, envolviam o mesmo assunto ou idéia, mas eram escritos de formas diferentes. Essa estratégia foi adotada visando verificar a consistência das respostas dos participantes para tais itens.

As respostas aos itens foram organizadas numa escala que variava de 1 ("Essa frase me descreve muito pouco") a 5 ("Essa frase me descreve bastante bem"). $\mathrm{O}$ valor 3 da escala referia-se a "Essa frase não me descreve nem bem nem mal". Portanto, considerou-se que optar por essa opção na avaliação de um item significava não assumir posição quanto a ele.

Os itens da escala foram divididos conceitualmente em cinco categorias, expostas abaixo:

Conceito de brincadeira (CONBRI): crenças e práticas dos professores que evidenciam seu conhecimento a respeito de conceito de brincar presente na literatura (11 itens). Ex: Procuro propor brincadeiras que as crianças gostem e se engajem de acordo com sua vontade.

Brincadeira e Aprendizagem (BRINCAPREND): valor atribuído pelos professores à brincadeira quando utilizada juntamente com atividades acadêmicas (que objetivam a alfabetização) (5 itens). Ex: Para mim, as brincadeiras são um excelente recurso didático para ajudar as crianças a aprender.

Papel dos professores nas situações de brincadeira livre e estruturada (PAPPROF): comportamentos que expressam a ação pedagógica do professor nas situações de brincadeira (9 itens). Ex: As atividades de ensino (acadêmicas) me exigem mais esforço e empenho do que as brincadeiras.

Dificuldades encontradas na utilização da brincadeira (DIFIPROF): dificuldades encontradas pelos professores quando utilizam a brincadeira, relaciona- 
das ao ambiente físico, à proposta pedagógica da escola e à mediação de interações sociais na sala (7 itens). Ex: Se a creche prioriza o ensino, a alfabetização, ainda assim incluo brincadeiras em meu planejamento.

Valor atribuído à brincadeira para o desenvolvimento global da criança (DESENBRI): crenças e práticas dos professores a respeito da importância da brincadeira para o desenvolvimento global (físico, cognitivo, social e emocional) (10 itens). Ex: Considero importante a brincadeira porque permite que as crianças exercitem o convívio social.

\section{Procedimento de coleta dos dados}

Após o projeto ter sido aprovado pelo Comitê de Ética em Pesquisas com Seres Humanos (protocolo $n^{\circ}$ 163/04), iniciou-se a coleta dos dados. Em cada escola, os participantes eram reunidos em uma sala e a cada um era entregue um questionário juntamente com o Consentimento Livre e Informado. Em cada instituição um dos pesquisadores dava as orientações necessárias e em seguida os participantes preenchiam o instrumento. As dúvidas que surgiam durante a aplicação eram esclarecidas individualmente pelos pesquisadores. Os participantes despenderam cerca de 20 minutos em média para responder o material.

\section{Análise dos dados}

Para o processamento das respostas, foi montado um banco de dados no programa estatístico SPSS (Statistical Package for Social Sciences - Versão 10.0). Primeiramente, foram estimadas as médias para os valores deixados em branco (missing values), utilizando-se o método da tendência linear ao ponto. Com isso feito, os dados foram submetidos a uma análise estatística descritiva, calculando-se, em cada item, a porcentagem de respostas dadas pelos professores a cada ponto da escala. Essa forma de tratamento de dados foi adotada em função de dois objetivos: efetuar uma primeira etapa de avaliação dos itens e das categorias, já que a escala é nova e ainda não passou por um processo de validação, e especificar a adesão a cada item, de forma a identificar as diferentes concepções existentes entre os professores.

\section{RESULTADOS}

Para a análise dos resultados obtidos nos itens pertencentes às diferentes categorias, admitiu-se concordância entre os professores nos itens que tiveram no mínimo $70 \%$ das respostas concentradas em um dos pólos da escala (considerando-se que cada pólo é composto pelos pontos $1 / 2$ e 4/5). Já nos itens em que a porcentagem de respostas foi significativa não só nos pólos, mas também em outros pontos da escala, admitiu-se heterogeneidade de concepções por parte dos participantes. Abaixo seguem os resultados em cada categoria, os quais estão resumidos nas tabelas 1 , $2,3,4$ e 5 . Foram grifados os valores numéricos nos itens em que houve concentração de respostas em um dos pólos da escala.

\section{Conceito de brincadeira (CONBRI)}

Algumas concepções a respeito do conceito de brincadeira foram compartilhadas entre os professores, dentre elas: o brincar como uma atividade prazerosa para a criança (item 1), estando diretamente relacionado às várias instâncias do desenvolvimento infantil (itens 7 e 24), sendo realizado tendo em vista uma satisfação que consiste nessa própria realização (item 34) e não estando ligado às noções de dever e obrigatoriedade (item 37). Ainda, constatou-se que grande parte dos professores utiliza a brincadeira de faz-de-conta durante suas atividades com as crianças (item 18) e que há concordância a respeito da idéia de que não somente as brincadeiras com regras explícitas propiciam um espaço para investigação e construção do conhecimento (item 25).

Curiosamente, apesar de os professores compartilharem tais concepções sobre o brincar, quando responderam aos itens complementares, envolvendo tipos, controle e regras das brincadeiras (itens 28, 29, 30 e 40), não foram concordantes entre si. Duas explicações podem ser dadas no momento para tal resultado: uma delas é a de que realmente há uma maior heterogeneidade de idéias a respeito dos conteúdos contidos nesses itens e outra seria a de que tais itens apresentam problemas semânticos que permitem diferentes entendimentos de seus conteúdos.

Os itens que apresentaram respostas heterogêneas, em sua maioria, evidenciam a prática dos professores relacionada ao conceito de brincadeira. São eles: item 29 , relacionado à utilização de brincadeiras competitivas (contrapondo-se a noção de que o brincar tem um fim em si mesmo); item 40 , relacionado à realização das atividades planejadas independente da vontade das crianças (contrapondo-se ao fato de o brincar não estar ligado à noção de dever); item 28 , relacionado às regras implícitas presentes na brincadeira de faz-deconta; e item 30, relacionado à utilização de brincadeiras que possuem regras claras. Após uma nova leitura desses itens, verificou-se que apenas o item 30 possui um problema semântico mais explícito, refe- 
rente à utilização do termo "regras claras". Este pode ter produzido dois diferentes entendimentos: o de que as brincadeiras com regras claras são aquelas classifi- cadas como brincadeiras de regras e o de que tais brincadeiras são aquelas em que o professor propõe de maneira clara, sem deixar dúvidas para as crianças.

Tabela 1. Porcentagem de respostas dos professores para cada um dos itens em relação aos diferentes pontos da escala na categoria "Conceito de Brincadeira"

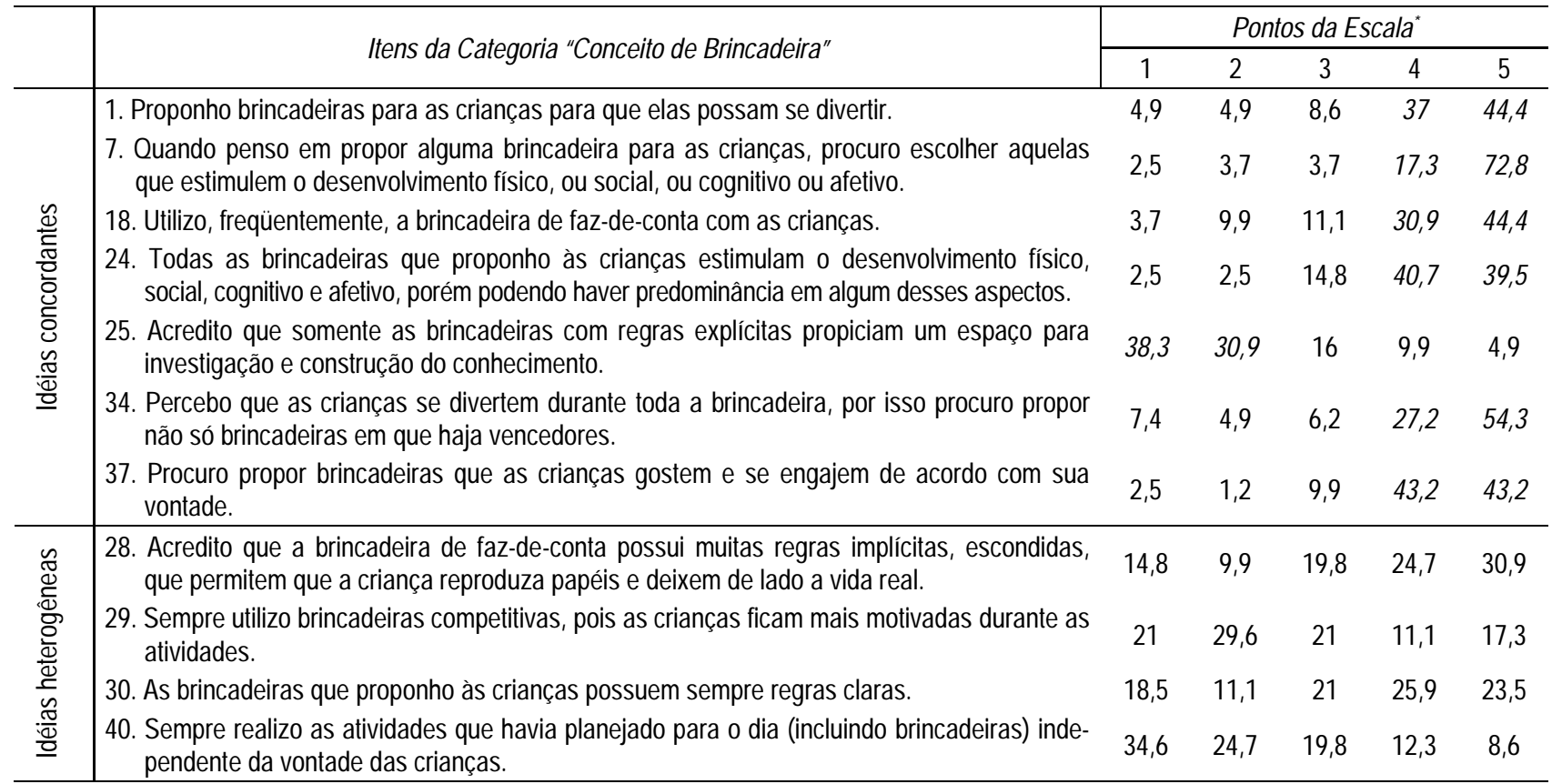

* 1 - Me descreve muito pouco; 2 - Me descreve pouco; 3 - Me descreve nem bem nem mal; 4 - Me descreve bem; 5 - Me descreve muito bem.

\section{Brincadeira e aprendizagem (BRINCAPREND)}

Nessa categoria, as respostas dos participantes a todos os itens concentraram-se nos pólos da escala, indicando que o conteúdo expresso em tais itens parece estar bem definido entre os professores. Primeiramente, verificou-se concordância entre os professores em relação à valorização tanto da utilização da brincadeira como da utilização de atividades de natureza acadêmica (itens 2 e 19). Uma forte associação entre brincadeira e aprendizagem também foi verificada, já que nos itens envolvendo esse aspecto (itens 6, 11 e 16) as respostas dos professores concentraram-se nos pólos da escala que evidenciavam tal associação. Nesse sentido, a brincadeira estaria sendo utilizada juntamente com atividades acadêmicas, como um recurso para ajudar as crianças a aprender, as quais, segundo os professores, ficam mais interessadas na aprendizagem quando ela é combinada à brincadeira.

Tabela 2. Porcentagem de respostas dos professores para cada um dos itens em relação aos diferentes pontos da escala na categoria "Brincadeira e Aprendizagem"

\begin{tabular}{|c|c|c|c|c|c|c|}
\hline & \multirow{2}{*}{ Itens da categoria "Brincadeira e Aprendizagem" } & \multicolumn{5}{|c|}{ Pontos da Escala* } \\
\hline & & 1 & 2 & 3 & 4 & 5 \\
\hline \multirow{5}{*}{ 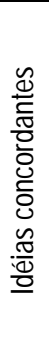 } & $\begin{array}{l}\text { 2. Prefiro propor atividades de natureza acadêmica, com lápis, papel e tintas, a propor atividades } \\
\text { de caráter "não sério" como a brincadeira. }\end{array}$ & 48,1 & 22,2 & 16 & 8,6 & 4,9 \\
\hline & 6. Para mim, as brincadeiras são um excelente recurso didático para ajudar as crianças a aprender. & 0 & 1,2 & 1,2 & 16 & 81,5 \\
\hline & $\begin{array}{l}\text { 11. Quando estou ensinando, evito a utilização de brincadeiras para não dispersar a atenção das } \\
\text { crianças e ajudá-las a fixar melhor o conteúdo. }\end{array}$ & 61,7 & 17,3 & 9,9 & 4,9 & 6,2 \\
\hline & $\begin{array}{l}\text { 16. Quando ensino um assunto novo utilizando a brincadeira, noto que as crianças ficam mais } \\
\text { interessadas. }\end{array}$ & 3,7 & 0 & 3,7 & 22,2 & 70,4 \\
\hline & $\begin{array}{l}\text { 19. Valorizo tanto os momentos de realização de tarefas sérias, quanto o tempo destinado para a } \\
\text { brincadeira. }\end{array}$ & 7,4 & 4,9 & 6,2 & 24,7 & 56,8 \\
\hline
\end{tabular}

* 1 - Me descreve muito pouco; 2 - Me descreve pouco; 3 - Me descreve nem bem nem mal; 4 - Me descreve bem; 5 - Me descreve muito bem. 


\section{Papel dos professores em situação de brincadeira livre e estruturada (PAPPROF)}

As respostas dos professores foram concordantes em apenas quatro itens referentes ao seu papel em situações de brincadeira. No item 14, pode-se verificar que grande parte dos professores gosta da sugestão de brincadeiras por parte das crianças em situações de ensino-aprendizagem. Também se constatou que a maioria dos professores não deixa de monitorar as crianças nas brincadeiras livres (item 15) e que nas situações de brincadeira de faz-de-conta, a maior parte deles deixa as crianças livres para escolherem seus papéis (item 22). Por fim, através das respostas ao item 42 , verificou-se que os professores foram concordantes em relação a uma melhor percepção das características das crianças nas situações de brincadeira do que nas atividades de ensino.

Tabela 3. Porcentagem de respostas dos professores para cada um dos itens em relação aos diferentes pontos da escala na categoria "Papel do Professor"

\begin{tabular}{|c|c|c|c|c|c|c|}
\hline & \multirow{2}{*}{ Itens da categoria "Papel do Professor" } & \multicolumn{5}{|c|}{ Pontos da Escala* } \\
\hline & & 1 & 2 & 3 & 4 & 5 \\
\hline \multirow{4}{*}{ 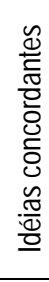 } & $\begin{array}{l}\text { 14. Gosto quando as crianças sugerem brincadeiras que podem ser utilizadas junto com os } \\
\text { assuntos que estão sendo ensinados. }\end{array}$ & 6,2 & 2,5 & 7,4 & 24,7 & 59,3 \\
\hline & 15. Mesmo durante as brincadeiras livres, não deixo de monitorar as crianças. & 6,2 & 6,2 & 8,6 & 27,2 & 51,9 \\
\hline & $\begin{array}{l}\text { 22. Quando proponho brincadeiras de faz de conta, deixo as crianças livres para escolherem } \\
\text { seus papéis. }\end{array}$ & 1,2 & 6,2 & 9,9 & 22,2 & 60,5 \\
\hline & $\begin{array}{l}\text { 42. Consigo perceber mais facilmente as características de cada criança em situação de brinca- } \\
\text { deira do que nas atividades de ensino. }\end{array}$ & 3,7 & 6,2 & 13,6 & 27,2 & 49,4 \\
\hline \multirow{5}{*}{ 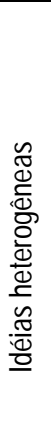 } & $\begin{array}{l}\text { 3. As atividades de ensino (acadêmicas) me exigem mais esforço e empenho do que as brinca- } \\
\text { deiras. }\end{array}$ & 28,4 & 23,5 & 30,9 & 7,4 & 9,9 \\
\hline & $\begin{array}{l}\text { 10. Prefiro eu mesma propor a maneira de realizar as atividades de ensino quando envolvem a } \\
\text { brincadeira. }\end{array}$ & 32,1 & 24,7 & 23,5 & 11,1 & 8,6 \\
\hline & $\begin{array}{l}\text { 35. Quando proponho brincadeiras de faz-de-conta oriento as crianças na escolha dos papéis, } \\
\text { levando em conta o conhecimento que tenho das habilidades de cada uma delas. }\end{array}$ & 19,8 & 12,3 & 29,6 & 22,2 & 16 \\
\hline & $\begin{array}{l}\text { 36. Nas brincadeiras livres minha função é organizar o espaço e disponibilizar os brinquedos } \\
\text { para as crianças. }\end{array}$ & 12,3 & 7,4 & 16 & 30,9 & 33,3 \\
\hline & $\begin{array}{l}\text { 41. Durante o período em que as crianças permanecem em sala, reservo um espaço para as } \\
\text { brincadeiras livres, no qual as crianças possam ficar a vontade, deixando-me livre para des- } \\
\text { cansar. }\end{array}$ & 32,1 & 11,1 & 11,1 & 14,8 & 30,9 \\
\hline
\end{tabular}

* 1 - Me descreve muito pouco; 2 - Me descreve pouco; 3 - Me descreve nem bem nem mal; 4 - Me descreve bem; 5 - Me descreve muito bem.

Os demais itens dessa categoria obtiveram respostas distribuídas pelos pontos da escala. Após uma nova leitura desses itens, pode-se perceber que nenhum deles possui erro semântico explícito, indicando que o conteúdo dos itens, na prática, provavelmente suscita diferentes posicionamentos. Inicialmente, verificou-se que as respostas dos professores ao item referente a um maior grau de esforço despendido nas atividades de ensino (estruturadas) do que nas brincadeiras (item 3) não se concentraram em um dos pólos da escala, já que 30,9\% dos respondentes não tomou posição quanto a essa questão.

Quanto aos itens referentes às atividades estruturadas utilizando à brincadeira (itens 10 e 14), verificouse que apesar de os professores gostarem que as crianças sugiram brincadeiras nessas situações (como já descrito acima), não há um elevado grau de concor- dância a respeito da preferência ou não por eles mesmos proporem as atividades de ensino quando envolvem a brincadeira (item 14).

Os demais itens referiam-se ao papel exercido pelos professores nas brincadeiras livres, incluindo o faz-de-conta. Houve grande discordância entre os professores quanto à possibilidade de descanso enquanto as crianças brincam livremente (item 41), assim como houve maior distribuição das respostas no item referente à sua função nessas situações (organização do espaço e disponibilização de brinquedos) (item 36). Já nas situações de faz-de-conta, as respostas dos professores foram bastante heterogêneas para o item 35, o qual se refere à função do professores de orientar as crianças na escolha dos papéis, levando em conta o conhecimento que o professor tem das habilidades de cada uma delas. 


\section{Dificuldades encontradas na utilização da brincadeira (DIFIPROF)}

Os itens distribuíram-se em três subcategorias envolvendo possíveis dificuldades dos professores na implementação da brincadeira: ambiente físico, proposta pedagógica da creche e mediação de interações sociais no brincar. A subcategoria ambiente físico incluiu tanto as dimensões da sala de aula, como a disponibilidade de brinquedos. As respostas dadas pelos professores ao item 4 permitem verificar concepções bastante heterogêneas quanto a questão do tamanho da sala visto como uma possível dificuldade na implementação do brincar. Já com relação aos brinquedos disponíveis, verificou-se que mesmo com a falta deles, a maior parte dos professores não deixa de propor brincadeiras (item 13). No entanto, as respostas ao item 26, o qual também se referia à questão dos brinquedos, distribuíram-se pelos pontos da escala. Após uma nova leitura do item, percebeu-se que a heterogeneidade de respostas poderia estar relacionada a uma diversidade de entendimentos do conteúdo do item, o qual não explicitava a inclusão ou não do brincar como fazendo parte das atividades que poderiam ser propostas em caso de falta de brinquedos.

Tabela 4. Porcentagem de respostas dos professores para cada um dos itens em relação aos diferentes pontos da escala na categoria "Dificuldades de Implementação do Brincar"

\begin{tabular}{|c|c|c|c|c|c|c|}
\hline & \multirow{2}{*}{ Itens da categoria "Dificuldades na Implementação do Brincar" } & \multicolumn{5}{|c|}{ Pontos da Escala* } \\
\hline & & 1 & 2 & 3 & 4 & 5 \\
\hline \multirow{4}{*}{ 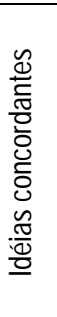 } & $\begin{array}{l}\text { 8. Utilizo brincadeiras para ajudar as crianças a desenvolver o autocontrole, colaborando assim, } \\
\text { para a diminuição da agressividade. }\end{array}$ & 3,7 & 0 & 11,1 & 29,6 & 55,9 \\
\hline & $\begin{array}{l}\text { 13. Mesmo com a falta de brinquedos, não deixo de propor brincadeiras, utilizando minha criati- } \\
\text { vidade e os materiais disponíveis. }\end{array}$ & 3,7 & 2,5 & 7,4 & 22,2 & 64,2 \\
\hline & $\begin{array}{l}\text { 17. Tenho dificuldade em incluir mais brincadeiras nas minhas atividades, porque noto que as } \\
\text { crianças se tornam agressivas e perdem o controle durante as brincadeiras. }\end{array}$ & 44,4 & 32,1 & 16 & 6,2 & 1,2 \\
\hline & $\begin{array}{l}\text { 21. Se a creche prioriza o ensino, a alfabetização, ainda assim incluo brincadeiras em meu } \\
\text { planejamento. }\end{array}$ & 4,9 & 2,5 & 4,9 & 24,7 & 63 \\
\hline \multirow{3}{*}{ 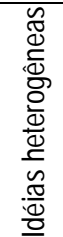 } & $\begin{array}{l}\text { 4. Gostaria de propor mais brincadeiras para as crianças, no entanto o espaço da sala de aula é } \\
\text { pequeno em relação ao número de crianças. }\end{array}$ & 29,6 & 9,9 & 14,8 & 29,6 & 16 \\
\hline & $\begin{array}{l}\text { 26. Muitas vezes, devido a falta de brinquedos, prefiro propor outras atividades utilizando os } \\
\text { materiais disponíveis em sala de aula (tinta, papel, lápis...). }\end{array}$ & 29,6 & 18,5 & 21 & 16 & 14,8 \\
\hline & $\begin{array}{l}\text { 31. Mesmo dando grande valor à brincadeira, acabo priorizando o ensino, as atividades acadê- } \\
\text { micas, em função da proposta pedagógica da creche na qual trabalho. }\end{array}$ & 28,4 & 21 & 23,5 & 22,2 & 4,9 \\
\hline
\end{tabular}

Um par de itens complementares da categoria está relacionado à proposta pedagógica da creche como uma possível barreira na implementação do brincar (itens 21 e 31). No item 21, as respostas concentraram-se nos dois últimos pontos da escala, indicando que a maior parte dos professores inclui brincadeiras em seu planejamento, apesar de a creche priorizar a alfabetização. Já no item 31 , houve distribuição das respostas pelos pontos da escala, a qual pode ser justificada pela possibilidade de o conteúdo do item não deixar explícito se priorizar a alfabetização em função da proposta pedagógica da creche significa ou não descartar a utilização das brincadeiras.

Os únicos itens complementares desta categoria que obtiveram respostas consistentes foram aqueles relacionados às mediações das interações sociais na brincadeira envolvendo agressividade ou perda de controle por parte das crianças (itens 8 e 17). As res- postas dadas a esses itens indicam que os professores concordam entre si que a mediação das interações no brincar não pode ser considerada uma barreira na implementação deste.

\section{Valor atribuído à brincadeira para 0 desenvolvimento global da criança (DESENBRI)}

As quatro grandes áreas do desenvolvimento (físico, social, cognitivo e emocional) foram relacionadas à brincadeira, a fim de perceber se os professores reconhecem sua funcionalidade para o desenvolvimento global da criança. Nos itens complementares referentes à importância da brincadeira para o desenvolvimento social (itens 5 e 20) e emocional (itens 33 e 39) as respostas foram bastante concentradas em um dos pólos da escala, indicando que os professores são concordantes em relação a tal importância. Ainda, com relação ao aspecto social, foram incluídos itens envol- 
vendo o manejo do professor frente aos papéis desenvolvidos pelas crianças durante a brincadeira (itens 23 e 32). Apesar de se ter verificado inconsistência nas respostas dadas a esses itens, admitiu-se que tal inconsistência deveu-se ao fato de que não necessariamente o conteúdo dos itens é complementar.

Tabela 5. Porcentagem de respostas dos professores para cada um dos itens em relação aos diferentes pontos da escala na categoria "Brincadeira e Desenvolvimento"

\begin{tabular}{|c|c|c|c|c|c|c|}
\hline & \multirow{2}{*}{ Itens da categoria "Brincadeira e Desenvolvimento" } & \multicolumn{5}{|c|}{ Pontos da Escala* } \\
\hline & & 1 & 2 & 3 & 4 & 5 \\
\hline \multirow{6}{*}{ 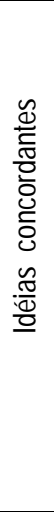 } & $\begin{array}{l}\text { 5. Considero importante a brincadeira porque permite que as crianças exercitem o convívio } \\
\text { social. }\end{array}$ & 0 & 1,2 & 1,2 & 14,8 & 82,7 \\
\hline & $\begin{array}{l}\text { 20. As atividades de ensino, por serem mais sérias e regradas, contribuem mais para que as } \\
\text { crianças exercitem o convívio social do que as brincadeiras. }\end{array}$ & 53,1 & 18,5 & 11,1 & 11,1 & 6,2 \\
\hline & $\begin{array}{l}\text { 27. Acredito que as brincadeiras ajudam as crianças a se desenvolver cognitivamente, no senti- } \\
\text { do que desenvolvem o raciocínio, a concentração, a criatividade, a imaginação, pensamento } \\
\text { abstrato, entre outros. }\end{array}$ & 1,2 & 1,2 & 4,9 & 16 & 76,5 \\
\hline & $\begin{array}{l}\text { 32. Consigo perceber, durante as brincadeiras, quem são os líderes e quem são os subordina- } \\
\text { dos (os mais quietos), assim procuro criar situações que façam surgir novos líderes. }\end{array}$ & 3,7 & 4,9 & 9,9 & 37 & 44,4 \\
\hline & $\begin{array}{l}\text { 33. Acredito que as brincadeiras ajudam as crianças a dominar suas angústias e controlar suas } \\
\text { idéias e impulsos. }\end{array}$ & 0 & 6,2 & 3,7 & 40,7 & 49,4 \\
\hline & $\begin{array}{l}\text { 39. Quando percebo que alguma criança está angustiada, triste, proponho uma brincadeira para } \\
\text { tentar ajudá-la. }\end{array}$ & 2,5 & 3,7 & 16 & 40,7 & 37 \\
\hline \multirow{4}{*}{ 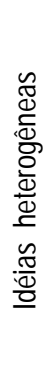 } & $\begin{array}{l}\text { 9. Freqüentemente, quando as crianças estão no pátio, proponho brincadeiras que envolvem } \\
\text { ações como o puxar, o levantar, o empurrar, o correr, o saltar, o rastejar, entre outros. }\end{array}$ & 16 & 13,6 & 21 & 24,7 & 24,7 \\
\hline & $\begin{array}{l}\text { 12. Não gosto quando as crianças estão muito agitadas, por isso, prefiro que se engajem em } \\
\text { brincadeiras mais calmas, como jogo de tabuleiro, quebra-cabeças, brincadeira de boneca } \\
\text { etc. }\end{array}$ & 24,7 & 23,5 & 21 & 19,8 & 11,1 \\
\hline & $\begin{array}{l}\text { 23. Por já conhecer quem são os líderes entre as crianças, sempre os utilizo para me auxiliar em } \\
\text { várias atividades. }\end{array}$ & 25,9 & 19,8 & 23,5 & 12,3 & 18,5 \\
\hline & $\begin{array}{l}\text { 38. As atividades de ensino que proponho ajudam as crianças a desenvolver o raciocínio e } 0 \\
\text { pensamento abstrato, enquanto que as brincadeiras proporcionam momentos de alegria para } \\
\text { as crianças. }\end{array}$ & 11,1 & 16 & 19,8 & 34,6 & 18,5 \\
\hline
\end{tabular}

* 1 - Me descreve muito pouco; 2 - Me descreve pouco; 3 - Me descreve nem bem nem mal; 4 - Me descreve bem; 5 - Me descreve muito bem.

Dois itens da categoria expressam em seu conteúdo a relação existente entre a brincadeira e o desenvolvimento cognitivo (itens 27 e 38). No item 27, a concentração de respostas nos último ponto da escala indica que os professores concordam que a brincadeira ajuda as crianças a desenvolver habilidades cognitivas, tais como o raciocínio, a concentração, a criatividade, imaginação. Já no item 38 , que relacionava o desenvolvimento cognitivo com as atividades de ensino e a brincadeira com momentos de alegria, as respostas dos professores foram bastante heterogêneas. Esse resultado pode ser justificado pelo fato de que a afirmação contida neste item pode ter sido considerada inadequada para alguns professores e adequada para outros, já que ambas as respostas podem ser aceitas.

Por último, nos dois itens envolvendo a importância do brincar para o desenvolvimento físico (itens $9 \mathrm{e}$ 12) as respostas dos professores foram bastante heterogêneas, distribuindo-se pelos cinco pontos da escala.
No item 9, é provável que a distribuição das repostas deva-se a utilização de termos como puxar e empurrar para caracterizar brincadeiras físicas, os quais podem ter fornecido um sentido negativo ao item. O item 12, após ter sido novamente analisado, não mostrou erros semânticos explícitos, indicando que provavelmente não há concordância entre os professores a respeito da utilização de brincadeiras mais calmas em função do não gostar da agitação das crianças.

\section{DISCUSSÃO}

O objetivo desse estudo foi caracterizar as concepções que professores de educação infantil têm a respeito da importância da brincadeira como parte do processo educativo. Resumidamente, os resultados indicaram que, apesar de os professores concordarem entre si a respeito de aspectos teóricos do conceito e da funcionalidade do brincar, há maior heterogeneidade de idéias relacionadas à implementação da brincadeira no cotidiano da educação infantil. Com relação a 
esse último aspecto, verificaram-se respostas heterogêneas acerca do papel do professor frente a diferentes situações de brincadeira, assim como contradições entre algumas respostas relacionadas às dificuldades na implementação do brincar. Outro resultado importante refere-se ao alto grau de concordância dos professores a respeito da associação do brincar à aprendizagem, o qual foi considerado um importante recurso didático no processo de alfabetização.

\section{Conceito de brincadeira}

As respostas dos professores referentes ao conceito de brincadeira mostram que alguns aspectos parecem estar bastante definidos entre eles, tais como: o fato de o brincar ser uma atividade prazerosa para a criança, estar diretamente relacionado às várias instâncias do desenvolvimento infantil, ser realizado tendo em vista uma satisfação que consiste nessa própria realização e não estar ligado a noção de dever, obrigatoriedade. Tal definição do brincar vai ao encontro das definições dos professores de educação infantil participantes do estudo de Cooney (2004). Neste caso, os professores definiram o brincar como atividades associadas ao desenvolvimento social, motor e cognitivo, as quais motivam as crianças porque são interessantes e prazerosas para elas. Ainda, citam algumas funções específicas do brincar, como: diminuição da tensão, divertimento, desenvolvimento da imaginação e aprendizagem.

Outro aspecto importante do conceito de brincar refere-se às regras presentes nas brincadeiras. Apesar de os professores terem sido concordantes entre si a respeito de que não só as brincadeiras com regras explícitas são importantes para a construção do conhecimento das crianças, suas respostas foram heterogêneas com relação às regras implícitas presentes no faz-de-conta e de sua funcionalidade. Vygotsky (1984) afirma que a brincadeira está relacionada ao desenvolvimento, pois quando a criança brinca, ela se comporta de forma mais avançada do que nas atividades da vida real e aprende a separar objeto de significado, e muito desse comportamento mais avançado deve-se às regras existentes em todas as brincadeiras, tanto regras explícitas como implícitas. Portanto, fazse necessário destacar a importância do reconhecimento do professor acerca de tais características do brincar, uma vez que são elas que permitem compreender a relação existente entre a brincadeira e o desenvolvimento, ou seja, de que forma a estrutura da brincadeira permite à criança desenvolver-se nos vários aspectos.

Interação em Psicologia, Curitiba, jul./dez. 2006, (10)2, p. 273-285
Nos itens que evidenciavam a prática dos professores em função do conceito de brincadeira (tais como a inclusão de brincadeiras competitivas e propostas de brincadeiras independente da vontade das crianças) houve maior heterogeneidade de respostas. Tais resultados indicam, portanto, que apesar de os professores terem conhecimento teórico a respeito do conceito de brincadeira, nem sempre tal conhecimento é vinculado à sua prática. $\mathrm{O}$ que então estaria por detrás dessa contradição existente entre teoria e prática?

Triandis (1971) afirma que o comportamento não é determinado somente pelo que as pessoas gostariam de fazer, mas também pelos que elas pensam que devem fazer (normas sociais), pelo que elas geralmente têm feito (hábitos), e pelas consequiências esperadas de seu comportamento. Nesse sentido, Goldhaber (1994), afirma que, apesar de os graduandos de Pedagogia serem treinados a valorizar a autonomia das crianças em sua aprendizagem e a brincadeira facilitada pelo professor como um meio de aprender, muitos encontram dificuldade de explicar suas práticas para seus colegas, pais e administradores. Sabe-se que atualmente há uma expectativa da sociedade como um todo com relação à precoce inserção da criança no meio acadêmico, fato este corroborado pela nova Lei de Diretrizes e Bases da Educação Nacional (Lei 11.274, de 06.02.2006) a respeito da inclusão de mais um ano no Ensino Fundamental, começando obrigatoriamente a partir dos 6 anos. A criança desde muito cedo já é solicitada a apresentar resultados concretos de sua aprendizagem, como a escrita, a leitura, o desenho; o que, provavelmente, é refletido no comportamento do professor. A partir disso, é possível levantar a hipótese de que o brincar ainda não é encarado como um meio efetivo para a criança desenvolver-se, visto que há uma dificuldade em se demonstrar concretamente a pais, professores, cuidadores os seus reais benefícios.

\section{Valor atribuído à brincadeira para o desenvolvimento global da criança}

A brincadeira foi considerada importante para o desenvolvimento social, uma vez que, segundo os professores, contribui para o convívio social das crianças, dando aos professores a oportunidade de identificar lideranças e fazer surgir novas. Pesquisadores têm enfatizam a contribuição do brincar para o aspecto social do desenvolvimento infantil (Bruner, 1972; Dohme, 2003; Kishimoto, 1988; Moraes, 2001). Segundo eles, a brincadeira permite a aprendizagem de vários comportamentos em uma relação de baixo risco, tais como: tirar proveito de suas habilidades, res- 
gatar valores e sentimentos importantes para a vida adulta, negociar, conviver com regras, resolver conflitos. Ainda Cordazzo (2003) e Dohme (2003) enfatizam a possibilidade de, na brincadeira, a criança comunicar-se com outros, fazendo as primeiras amizades.

Os professores também foram concordantes com relação à importância da brincadeira para o desenvolvimento emocional, quando consideraram que, ao brincar, a criança aprende a dominar suas angústias e a controlar suas idéias e impulsos. Cordazzo (2003) afirma que através da brincadeira as crianças podem exprimir a sua agressividade e dominar suas angústias; além de, segundo Lopes (2000), trabalhar a ansiedade e reduzir a descrença na autocapacidade de realização.

Como já exposto na sessão de resultados, houve heterogeneidade de respostas no item referente à utilização de brincadeiras que envolvem ações como o puxar, o levantar, o empurrar, o correr, o saltar, o rastejar, entre outros, assim como no item referente à utilização de brincadeiras mais calmas. Apesar de se ter verificado que essa heterogeneidade pode estar relacionada à utilização de termos com sentido negativo (empurrar, por exemplo), ainda assim é importante destacar a importância desse tipo de brincadeira. Esses comportamentos caracterizam o que Pellegrini e Smith (1998) denominam de "Exercise Play" (brincadeira motora ampla). Segundo eles, esse tipo de brincadeira inicia ao final do primeiro ano de vida e tem seu pico entre 4 e 5 anos, ou seja, em idade préescolar. Além disso, afirmam que tais atividades auxiliam as crianças a desenvolver o vigor físico, a força, e possivelmente, segundo evidências recentes por eles apresentadas, propiciam ao indivíduo a redução de gordura e auxiliam na termorregulação. Diante de tais benefícios, seria de extrema importância para o desenvolvimento da criança que tais comportamentos fossem valorizados e incentivados durante o período pré-escolar. Essa idéia é reforçada pelo fato de que, em crianças com idade entre 6 a 10 anos, a frequiência desse tipo de brincadeira tende a decair, uma vez que o espaço bastante denso das salas de aula poderia inibir as atividades envolvendo movimentos motores amplos (Pellegrini, 1990; Smith \& Connolly, 1980).

Já com relação à questão da importância da brincadeira para o desenvolvimento cognitivo, os professores concordaram entre si que ela ajuda as crianças a desenvolver o raciocínio, a concentração, a criatividade, a imaginação, pensamento abstrato, entre outros. Em outro item referente a essa questão as respostas foram mais heterogêneas possivelmente em função de problemas no conteúdo do item. Todavia, faz-se ne- cessário discutir a respeito das situações em que a brincadeira é considerada importante para o desenvolvimento cognitivo, uma vez que, conforme verificado na categoria "Brincadeira e Aprendizagem", há uma maior tendência de associar a brincadeira a essa instância do desenvolvimento somente quando esta é utilizada com um fím didático específico.

A brincadeira por si só não estaria relacionada ao desenvolvimento cognitivo? Dohme (2003) enfatiza que as brincadeiras podem provocar o desenvolvimento cognitivo de forma direta, através de jogos cujo objetivo envolva inteligência e raciocínio; e de forma indireta, usando-se o raciocínio estratégico para a conquista de um objetivo, seja ele físico, artístico etc. Muitas brincadeiras que envolvem números, charadas, utilizam o raciocínio lógico, o pensamento abstrato, rapidez de raciocínio, e ao mesmo tempo, se combinadas com atividades que requeiram ação, entusiasmam as crianças (Dohme, 2003). Ainda, Dias (1999) aponta que a imaginação em ação ou o brinquedo é a primeira possibilidade de ação das crianças numa esfera cognitiva que lhe permite ultrapassar a dimensão perceptiva motora do comportamento. A mesma autora afirma que também o jogo simbólico fornece a primeira possibilidade de pensamento propriamente dito, marcando a passagem de uma inteligência sensório motora, baseada nos cinco sentidos e na motricidade, para uma inteligência representativa pré-operatória (material e intuitiva).

\section{Papel dos professores em situações de brincadeira livre e estruturada}

Quanto às atividades estruturadas utilizando a brincadeira, os professores foram concordantes acerca da aceitação de sugestões de brincadeiras por parte das crianças, no entanto em relação ao item complementar ("Prefiro eu mesma propor a maneira de realizar as atividades de ensino quando envolvem brincadeira".) houve maior heterogeneidade de respostas. Tal contradição traz evidências de que, quando os professores utilizam a brincadeira para fins específicos, a liberdade do brincar é relegada a um segundo plano e, portanto, ele perde seu sentido original. Kishimoto (1994) afirma que é preciso que a ação pedagógica intencional do professor não entre em conflito com a ação voluntária da criança, no sentido de preservar a sua liberdade. Portanto, mesmo com um fim específico a brincadeira somente exercerá sua funcionalidade e será atrativa para a criança caso suas características sejam mantidas. 
Quais seriam as ações dos professores adequadas para esse fim? As respostas dos professores para os itens envolvendo as brincadeiras livres permitem identificar heterogeneidade de idéias sobre as suas intervenções durante as brincadeiras, incluindo a organização do espaço, disponibilização dos brinquedos, escolha de papéis durante a brincadeira de faz de conta, e a opção ou não pelo descanso enquanto as crianças brincam. Dessa forma, se há dúvidas referentes ao papel do professor nas brincadeiras livres relacionadas à questão da manutenção da liberdade da criança, tais dúvidas tendem a ser bem maiores em situações de brincadeiras estruturadas. Como possível explicação, pode-se pensar que a falta de conhecimento e reflexão dos professores sobre a relação brincadeira-desenvolvimento, ou seja, sobre como a estrutura da brincadeira atua para ampliar o nível de desenvolvimento da criança, poderia estar por detrás dessas dificuldades. Nesse sentido, Esteban (1992, p. 76) afirma que: "A concepção que o professor tem de mundo e de homem tem relação com sua concepção sobre o processo de alfabetização, assim como a leitura que faz do desenvolvimento da criança tem relação com a qualidade de sua intervenção".

Olsen e Sumsion (2000) fornecem outra possível explicação para a dificuldade dos professores em relação à implementação da brincadeira. Os autores enfatizam a necessidade de exemplos práticos de como implementar a brincadeira adequadamente durante a formação dos professores, seja durante o curso superior ou em cursos extracurriculares, entre outros. A possibilidade de observar e participar de brincadeiras e de discussões a respeito de questões teóricas poderia contribuir tanto para uma formação mais adequada quanto para desenvolver no professor o gosto pelo brincar. Nesse sentido, alguns autores citam características consideradas essenciais para os professores que utilizam a brincadeira, tais como: entusiasmo, criatividade, alegria de viver, aptidão para relações humanas (Leif \& Brunelle, 1978).

Outro fator importante evidenciado dentre os resultados é a concordância dos professores com relação a sua melhor percepção das características das crianças em situação de brincadeira. Como no brincar a criança age na esfera da espontaneidade, torna-se importante que o professor, como principal ação, observe os momentos de brincadeira visando compreender o mundo da criança, seus esforços para compreender esse mundo, suas habilidades não percebidas em outros momentos. Essa idéia é defendida por Goldhaber (1994), a qual afirma que o brincar deve ser mais digno de atenção, uma vez que compara a criança enquanto brinca a um cientista. A observação, dessa forma, possibilitaria ao professor aprender o modo mais adequado de intervir com relação à determinada criança, e até mesmo brincar com ela.

\section{Relação entre brincadeira e aprendizagem}

Os resultados referentes a essa questão permitem continuar a discussão anterior a respeito do papel dos professores nas situações de brincadeira. Isso porque uma forte associação entre brincadeira e aprendizagem foi revelada, e nesse sentido a brincadeira estaria sendo utilizada principalmente com atividades acadêmicas, como um recurso para ajudar as crianças a aprender. Portanto, os professores podem não estar cientes de seu papel de intervenção durante as brincadeiras em função da desvalorização das mesmas independentemente de um fim específico na aprendizagem.

Tal desvalorização vai ao encontro do lugar reservado á brincadeira no Referencial Curricular Nacional para a Educação Infantil (Brasil/MEC, 1998), visto que ela aparece como um importante componente da educação infantil, mas como uma ferramenta para a aprendizagem. Muito dessa ligação entre brincadeira e aprendizagem pode refletir a expectativa da escola em relação às crianças que ingressam no ensino fundamental. Souza (1996), a partir de descrições de professores e pais presentes em prontuários de crianças encaminhadas por dificuldade de aprendizagem, evidencia que há uma tendência desses educadores a apresentar uma concepção idealizada a respeito das crianças ingressantes. Segundo a autora, os educadores esperam que as crianças ingressem na escola com uma letra legível, coordenação motora adequada, escrevam sem pressionar em demasia o lápis ou ainda que já estejam em estágios avançados no processo de alfabetização, de maneira que um pequeno contato com as informações da professora seja suficiente para escreverem e lerem corretamente. Nesse sentido, Kishimoto (1997) afirma que tais objetivos da educação infantil expressam valores cultivados e reproduzidos pela escola e pela sociedade, ou seja, que estariam além das habilidades e prioridades particulares de cada professor.

\section{Dificuldades dos professores na implementação da brincadeira}

As respostas demonstraram que a proposta pedagógica da creche e as interações entre as crianças não 
foram consideradas, significativamente, barreiras na implementação da brincadeira. As questões de ambiente, no entanto, suscitaram maior heterogeneidade de respostas, o que pode estar refletindo diferenças reais, ou seja, diferenças nas condições físicas das creches pesquisadas. Apesar de alguns estudos citarem questões ambientais (recursos disponíveis, número de crianças por sala, tempo) como algumas dificuldades encontradas pelos professores (Cooney, 2004; Goldhaber, 1994; Olsen \& Sumsion, 2000), todos estes enfatizam que as principais barreiras localizam-se em questões pedagógicas, como a ausência de desenvolvimento profissional que enfoque o currículo orientado pela brincadeira (Cooney, 2004), que leve em conta cada contexto escolar e as dificuldades para implementar a brincadeira nesses contextos (Olsen \& Sumsion, 2000). Portanto, tal aperfeiçoamento deveria possibilitar aos professores instrumentalizá-los na utilização do brincar não só com fins didáticos, visando proporcionar para a criança a possibilidade de desenvolver-se globalmente, além de proporcionar ao professor a criação de recursos a fim de justificar suas práticas para a escola e para os pais.

\section{CONSIDERAÇÕES FINAIS}

Para que a brincadeira seja inserida efetivamente nos processos educativos é preciso, além de uma atitude favorável à mesma, uma mudança no comportamento que seja consoante com tal atitude. Embora uma mudança abrangente seja necessária (envolvendo aqueles que comandam as instituições escolares e estruturam a educação no país), isto não significa tirar a responsabilidade dos professores de educação infantil (incluindo aqueles que permanecem nas universidades) em relação à implementação da brincadeira, assim como de outras práticas também relevantes. É preciso que os professores reconheçam seu importante papel na determinação da qualidade dos programas de educação infantil, buscando meios para permitir a melhor forma de utilização da brincadeira nesse contexto.

Este estudo, ainda que pontual, permite a reflexão de como o brincar vem sendo encarado no contexto da educação infantil, podendo-se constatar quais os avanços já alcançados e o que ainda precisa ser feito nesse sentido. No entanto, não esgota a possibilidade de investigações na área. Pelo contrário, abre a possibilidade de novas pesquisas, organizadas aqui em três grupos: a) relação professor-criança - que inclui investigações acerca da possível associação entre a qua- lidade de intervenção do professor que utiliza a brincadeira e o desenvolvimento da criança nas várias áreas; b) o brincar livremente, objetivando investigar as contribuições que a brincadeira livre pode trazer para a criança, seja ela solitária ou em grupo; e c) contribuições posteriores do brincar, que inclui pesquisas a fim de investigar os efeitos que o brincar na educação infantil podem exercer nas aprendizagens posteriores, ou seja, na educação formal.

Ainda, é importante evidenciar o caráter exploratório do presente estudo, uma vez que fez uso de um instrumento de coleta de dados inédito, o qual necessita de um maior aperfeiçoamento. Para futuros estudos, sugere-se uma ampliação da amostra a fim de se realizar uma análise fatorial dos 42 itens, visando à utilização de índices mais criteriosos para a seleção dos itens pertinentes. Isso também possibilitaria a realização de análises mais apuradas e conseqüentemente a descoberta de outros resultados.

\section{REFERÊNCIAS}

Brasil/MEC (1998). Referencial curricular para a educação infantil. Brasília: MEC/SEF.

Bruner, J. (1972). The nature and uses of immaturity. American Psychologist, 27, 687-708.

Cooney, M. H. (2004). Is play important? Guatemalan kindergartners classroom experiences and their parent's and teacher's perceptions of learning through play. Journal of Research in Childhood Education, 18 (4), 261-277.

Cordazzo, S. T. D. (2003). Caracterização de brincadeiras de crianças em idade escolar. Dissertação de Mestrado, Universidade Federal de Santa Catarina, Florianópolis (SC).

Corzaro, W. \& Schwarz, K. (1991). Peer play and socialization in two cultures. Implications for research and practice. Em B. Sacales (Org.), Play and the social context of development in early care and education (p. 75-91). United States: Columbia University.

Dias, M. C. M. (1999). Metáfora e pensamento: considerações sobre a importância do jogo na aquisição do conhecimento e implicações para a educação pré-escolar. Em T. M. Kishimoto (Org.), Jogo, brinquedo, brincadeira e educação ( $\left.3^{\mathrm{a}} \mathrm{ed}.\right)$ (p. 45-56). São Paulo: Cortez.

Dohme, V. (2003). Atividades lúdicas na educação: o caminho de tijolos amarelos do aprendizado. Petrópolis: Vozes.

Esteban, M. T. (1992). Repensando o fracasso escolar. Cadernos Cedes 28 - O sucesso escolar: um desafio pedagógico (p. 7586). Campinas: Papirus.

Fein, G. (1978). Play revisited. Em M. E. Lamb (Org.), Social and personality development (p. 70-90). New York: Holt, Rinehart and Winston.

Goldhaber, J. (1994). If we call it science, then can we let the children play? Childhood Education, 77 (3), 24-27. 
Goldhaber, J. \& Smith, D. (1993). Infants and toodlers at play: looking for meaning. Day Care and Early Education, 20 (3), 912.

Hatch, J. A. \& Freeman, E. B. (1988). Kindergarten philosophies and practices: perspectives of teachers, principals, and supervisors. Early Childhood Research Quarterly, 3, 151-166.

Kishimoto, T. M. (Org.), (1988). O brincar e suas teorias. São Paulo: Pioneira.

Kishimoto, T. M. (1994). O jogo na educação infantil ( $3^{\mathrm{a}}$ ed.). São Paulo: Pioneira.

Kishimoto, T. M. (1997). Brinquedo e brincadeira na educação infantil japonesa: proposta curricular dos anos 90. Educação $e$ Sociedade, 18 (60), 64-88.

Kishimoto, T. M. (1999). Jogo, brinquedo,brincadeira e a educação ( $3^{\mathrm{a}}$ ed.). São Paulo: Cortez.

Leif, J. \& Brunelle, L. (1978). O jogo pelo jogo: as atividades lúdicas na educação de crianças e adolescentes. Rio de Janeiro: Zahar Editores.

Lopes, M. G. (2000). Jogos na educação: criar, fazer, jogar ( $3^{\mathrm{a}}$ ed.). São Paulo: Cortez.

Moraes, A. (2001). .Análise estrutural e funcional da brincadeira de crianças em idade pré-escolar. Dissertação de Mestrado, Universidade Federal de Santa Catarina, Florianópolis (SC).

Negrini, A. (1994). Aprendizagem \& desenvolvimento infantil: simbolismo e jogo. Porto Alegre: Prodil.

Olsen, A. E. \& Sumsion, J. (2000). Early childhood teacher practices regarding the use of dramatic play in K-2 classrooms. Trabalho apresentado na Conferência Anual da Associação Australiana de Pesquisa em Educação, Sydney.

Pellegrini, A. D. \& Smith, P. K. (1998). Physical activity play: the structure and function of a neglected aspect of play. Child Development, 69 (3), 577-598.
Pellegrini, A. D. (1990). Elementary school children's playground behavior: implications for social cognitive development. Children's Environment Quarterly, 7, 8-16.

Rosen, C. E. (1974). The effects of sociodramatic play on problem solving behavior among culturally disadvantaged children. Child Development, 45, 920-927.

Smith, P. K. \& Connoly, K. (1980). The ecology of preschool behavior. Cambridge: Cambridge University Press.

Snider, M. H. \& Fu, V. R. (1990). The effects of specialized education and job experience on early childhood teachers' knowledge of developmentally appropriate practice. Early Childhood Research Quarterly, 5 (1), 69-78.

Strickland, D. S. \& Ogle, D. M. (1990). Teachers coping with change: assessing the early literacy curriculum. Em L. M. Morrow \& J. K. Smith (Orgs.), Assessment for instruction in early literacy (p. 122-165). Englewood Cliffs, NJ: Prentice Hall.

Souza, M. P. R. (1996). Formação de psicólogos para o atendimento a problemas de aprendizagem: desafios e perspectivas. Estilos da Clínica - Instituto de Psicologia da USP, 1 (1),134154.

Triandis, H. C. (1971). Attitude and attitude change. New York: Wiley.

Vygotsky, L. S. (1984). A Formação Social da Mente (3ª ed.). São Paulo: Editora Martins Fontes.

Volpato, G. (2002). Jogo, brincadeira e brinquedo: usos e significados no contexto escolar e familiar. Florianópolis: Cidade Futura.

Recebido: 20/02/2006

Revisado: 31/05/2006

Aceito: 07/09/2006

\section{Nota:}

${ }^{1}$ Os valores de "n" que aparecem entre parênteses ao longo do texto referem-se ao número de respostas obtidas nas questões expostas, já que alguns participantes não as responderam.

\section{Sobre os autores:}

Gabriela Dal Forno Martins: Graduanda em Psicologia pela UFSC.

Mauro Luís Vieira: Professor Doutor do Departamento de Psicologia da UFSC.

Ana Maria Faraco de Oliveira: Professora Doutora associada ao Departamento de Psicologia da UFSC.

Endereço para correspondência: Departamento de Psicologia da Universidade Federal de Santa Catarina - Campus Universitário, Trindade - 88040-900 Florianópolis - SC - Endereço eletrônico: mvieira@cfh.ufsc.br. 